\title{
Effect of laminate configuration on the modulus of elasticity of glulam evaluated using a strain gauge method
}

Received: October 3, 2005 / Accepted: May 22, 2006 / Published online: October 26, 2006

\begin{abstract}
The purpose of this study was to measure the strain of glulam laminae by affixing a strain gauge at the central axis of the lateral face in order to determine the effect of the configuration of the glulam. Japanese cedar and southern pine were used in the study. The strain and stress of the laminae during the bending test were recorded, and the modulus of elasticity $(M O E)$ was calculated. The influence of the $M O E$ of the adhesive layers was also considered. Results showed that the $M O E$ of the laminated elements increased as its specific gravity increased, although the specific gravity was not the only factor evaluated. The $M O E$ of glulam $\left(E_{\mathrm{bsg}}\right)$ measured by the strain gauge method was very close to the observed $M O E$ of glulam $\left(E_{\mathrm{b}}\right)$ and a significant linear relationship was identified. The $M O E(e)$ of laminae measured by the strain gauge method was very close to that determined $(E)$ under the "free condition" before bonding. The difference between the modified $M O E$ $\left(E_{\mathrm{bsa}}\right)$ and $E_{\mathrm{bsg}}$ was not significant. The $M O E$ of glulams made of heterogeneously graded lumbers were about $23 \%$ and $31 \%$ larger than the average $M O E$ of their laminae for Japanese cedar and southern pine, respectively. The actual neutral axis was just below the longitudinal center line. It shifted slightly within the proportional limit range and moved downward when the load increased.
\end{abstract}

Key words Glulam • Configuration • Strain gauge • Lamination

T.-H. Yang $\cdot$ S.-Y. Wang $\cdot$ M.-J. Tsai $\cdot$ F.-C. Lin $(\bowtie)$

School of Forest Resource and Conservation, College of

Bio-Resource and Agriculture, National Taiwan University,

Taipei 106, Taiwan, ROC

Tel. +886-23-366-3848; Fax +886-22-365-4520

e-mail: farching@ntu.edu.tw

C.-J. Lin

Taiwan Forest Research Institute, Taipei, Taiwan, ROC

\section{Introduction}

A glulam is made up of wood laminae, which are bonded together with adhesive. Its members are composed of individual pieces of dimension lumber that are end-jointed, in which the grain of all laminations runs parallel with the length of the member. Glulam is used widely in Europe and North America because it is an engineered wood product and is manufactured to meet a range of design stresses and large span.

The laminae of glulam can be evaluated by nondestructive methods before they are used in glulam manufacture. ${ }^{1-5}$ After accurate design of the configuration, glulam can meet various structural requirements. In previous reports,${ }^{6,7}$ relationships of the lamina properties with visual grading, ultrasonic wave velocity, and transverse vibration were studied. Then the configuration of the glulam was designed based on the modulus of elasticity $(M O E)$ of each lamination.

The properties of laminae are the important key factor of glulam. The configurations, selection, and strength of the laminations were studied in an earliuer report of glulam design. Hernandez and Moody ${ }^{8}$ designed the configurations of glulam made of southern pine with a modulus of rupture $(M O R)$ of $20.58 \mathrm{MPa}$ and $M O E$ of $13720 \mathrm{MPa}$. They indicated that the glulam could be configured with the outer $10 \%$ of laminations being $E$-rated to have an $M O E$ of $15778 \mathrm{MPa}$, and the adjacent $15 \%$ of laminations being No.1D lumber with an average $M O E$ of $13720 \mathrm{MPa}$. Similar results were also found in the study of hardwood. Manbeck et al. ${ }^{9}$ and Janowiak et al. ${ }^{10}$ designed the configuration of glulam made from red maple with $M O R$ of $16.46 \mathrm{MPa}$ and $M O E$ of $12348 \mathrm{MPa}$. Moody et al. ${ }^{11}$ also designed a glulam made from yellow poplar with the same strength properties.

On the other hand, Falk ${ }^{12}$ compared the design of glulam made in the United States and Europe. He indicated that a single glulam may incorporate three or more different structural grades of lumber, sometimes of different species in the United States. In these engineered combinations, the highest-quality material is positioned in the member where 
the service load is expected to create the highest stress. Conversely, lower-grade laminations are positioned in the areas or zones where the stress is expected to be lower. This use of multiple species and several different grades within a single glulam is distinctly different from glulam design in Europe, where glulam design is limited to a single grade (homogeneous layup) or two grades (combined layup). The relationship of $M O R$ and $M O E$ is linear in European glulam while it is nonlinear in American glulam. Falk and Colling $^{13}$ also indicated that in the glulams in North America constructed with special tension laminations, the gradient of stiffness is sharper than that in the more homogenous combinations of European glulams. This results in lower glulam bending strengths at higher lamination tension strength levels and implies that European glulams possess a more efficient structural balance between lamination tensile strength and glulam bending strength.

Lee et al. ${ }^{14}$ configured ten different types of glulam with three different grades of laminations which followed the criteria of ASTM D3737. In these glulams, three types were homogenous while the other seven were heterogeneous. Results shows that the MOR and MOE of glulams occurred in the order of grade $1>$ grade $2>$ grade 3 in the homogeneous group. In the heterogeneous group, the highest strength glulam was configured with the highest grade as the outer lamination.

Although the target strength and differences between homogeneous and heterogeneous grades of glulam can be obtained through the configuration of laminations, the properties of interest are macromechanical properties and performance of the glulam rather than the laminations. The extent of research regarding the micromechanical properties of laminae including the stress-strain relationship in both homogeneous and heterogeneous grades of glulams is limited. In addition, the distribution of longitudinal stress within the laminae must also be confirmed in order to determine the neutral axis of the glulam. Hence, the purpose of this study was to measure the strain of the laminae by affixing a strain gauge at the central axis of the edge face. The strain and stress of laminae during bending were recorded, and the modulus of elasticity was calculated. The results were used to determine the effect of laminate configuration on the $M O E$ of glulam.

\section{Materials and methods}

\section{Test materials}

Two kinds of materials were used in the study: Japanese cedar (Cryptomeria japonica) and the southern pine (Pinus spp.). The lumber dimensions were $38 \times 89 \mathrm{~mm}$ in cross section and $3600 \mathrm{~mm}$ in length. The average air-dried densities of Japanese cedar and southern pine lumbers were 502 and $622 \mathrm{~kg} / \mathrm{m}^{3}$, respectively. A total of 144 pieces of Japanese cedar and 144 pieces of southern pine lumber were used, and each glulam was made of six elements. The average moisture content of the laminae was $14 \%$.

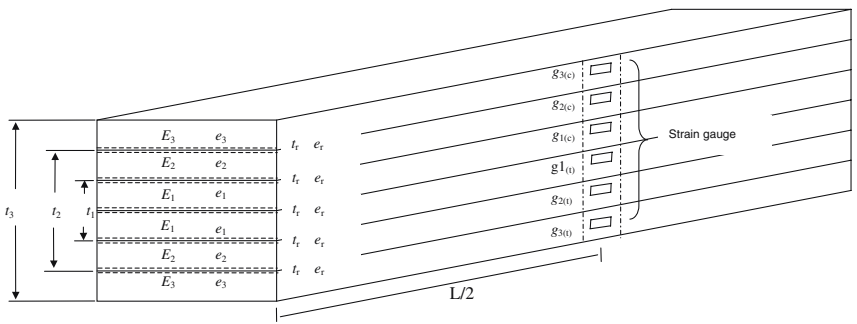

Fig. 1. Longitudinal section of glulam. $E_{1}, E_{2}, E_{3}$ the modulus of elasticity $(M O E)$ of laminae under free condition; $e_{1}, e_{2}, e_{3}$, the $M O E$ of laminae under constrained condition; $t_{\mathrm{r}}$, the thickness of adhesive layer; $e_{\mathrm{r}}$, the $M O E$ of adhesive layer; $t_{1}, t_{2}, t_{3}$, the thickness of inside layers, interlayers, and total layers of glulam; $g_{1(c)}, g_{2(c)}, g_{3(c)}, g_{1(t)}, g_{2(t)}, g_{3(t)}$, the strain gauge positions on the lamina

Test of laminae

All lumber was subjected to the four-point bending test, and the modulus of elasticity $\left(E_{1}-E_{6}\right)$ was calculated from the lumber deflection and relative proportional limit loading.

Configuration and manufacture of glulam

High- $M O E$ laminae were assigned to the top and bottom positions in order to manufacture a glulam with better mechanical properties. ${ }^{15}$ Hence, the study distinguished differences in glulam made with homogeneously graded lumber and heterogeneously graded lumber. Resorcinal resin adhesive (RF) was applied with a spreading rate of $0.323 \mathrm{~kg} / \mathrm{m}^{2}$ at a pressure of $0.98 \mathrm{MPa}$ when the glulam was manufactured by the radio frequency method.

The allocation of each lamina was based on its bending stiffness. ${ }^{16}$ Considering the effect of the adhesive layer, as shown in Fig. 1, the bending stiffness of the glulam was the summation of all bending stiffness values of the adhesive layers and laminae. ${ }^{17,18}$

$E_{\mathrm{b}} I=\sum\left(e_{j} I_{j}+e_{\mathrm{r} j} I_{\mathrm{r} j}\right)$

where $E_{\mathrm{b}}$ is the $M O E$ of glulam, $I$ is the moment of inertia of the glulam, $e_{j}$ and $I_{j}$ are the $M O E$ and moment of inertia of the $j$-th layer of the laminae, respectively, and $e_{\mathrm{r} j}$ and $I_{\mathrm{r} j}$ are the $M O E$ and moment of inertia of the $j$-th adhesive layer, respectively.

The glulam was made of six pieces of lumber in the study and considering the existence of the adhesive layers, $E_{\mathrm{b}}$ could be expressed as follows:

$$
\begin{aligned}
E_{\mathrm{b}}= & e_{3}-\left(e_{3}-e_{2}\right) \frac{t_{2}^{3}}{t_{3}^{3}}-\left(e_{2}-e_{1}\right) \frac{t_{1}^{3}}{t_{3}^{3}}+3 t_{r}\left(2 e_{r}-e_{3}-e_{2}\right) \frac{t_{2}^{3}}{t_{3}^{3}} \\
& +3 t_{r}\left(2 e_{r}-e_{2}-e_{1}\right) \frac{t_{1}^{3}}{t_{3}^{3}}
\end{aligned}
$$

The above formula was used to allocate the laminae of glulam in this study. All pieces of Japanese cedar lumber 


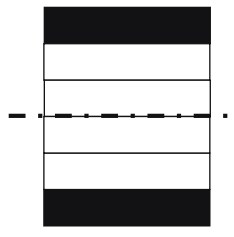

Heterogeneous group homogeneous group

(a)

GJI group

GSI group

GJ3H group

GS3H group

For Japanese cedar glulam:

- $13.7 \mathrm{GPa}$

$\square 11.8 \mathrm{GPa}$

$\square 10.8 \mathrm{GPa}$

$\square 9.3 \mathrm{GPa}$

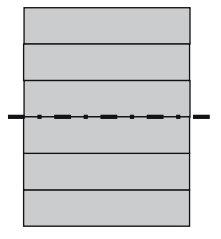

homogeneous group

(c)

GJ2H group

GS2H group

For Southern pine glulam:

— $19.6 \mathrm{GPa}$

$\square 17.6 \mathrm{GPa}$

$\square 14.7 \mathrm{GPa}$

$\square 11.8 \mathrm{GPa}$
Fig. 2a-d. Sectional compositions of a heterogeneous glulam and b-c homogeneous glulams of Japanese cedar and southern pine

were graded into four groups (see Fig. 2): the heterogeneously graded combined group GJI ( $M O E$ at $E_{3}$ was 13.7 $\mathrm{GPa}, M O E$ at $E_{1}$ and $E_{2}$ were both $9.3 \mathrm{GPa}$ ), and the homogeneously graded combined groups of GJ3H (MOE $11.8 \mathrm{GPa})$, GJ2H (MOE 10.8 GPa), and GJ1H $(M O E$ $9.3 \mathrm{GPa}$ ). Similarly, the pieces of southern pine lumber were also graded into four groups (Fig. 2): the heterogeneously graded combined group GSI $\left(M O E\right.$ at $E_{3}$ of $19.6 \mathrm{GPa}$, $M O E$ at $E_{1}$ and $E_{2}$ positions were both $11.8 \mathrm{GPa}$ ), and the homogeneously graded combined groups of GS3H $(M O E$ $17.6 \mathrm{GPa}), \mathrm{GS} 2 \mathrm{H}(M O E 14.7 \mathrm{GPa})$, and $\mathrm{GS} 1 \mathrm{H}(M O E$ $11.8 \mathrm{GPa})$.

Bending test and measurement of stress and strain

\section{Static bending test}

The bending test was carried out using the four-point loading method. The loading speed did not exceed $14.7 \mathrm{MPa} / \mathrm{min}$. The $M O E$ and $M O R$ can be expressed as follows:

$$
M O E=\frac{23 \Delta P L^{3}}{108 \delta b h^{3}}
$$

and

$$
M O R=\frac{P L}{b h^{2}}
$$

where $\Delta P$ is the difference between the upper and lower loading limits in the proportional limit region, $\delta$ is the deflection with respect to $\Delta P(\mathrm{~mm}), L$ is span $(\mathrm{mm}), b$ is the width of the glulam $(\mathrm{mm}), h$ is the thickness of the glulam $(\mathrm{mm})$, and $P$ is the maximum loading $(\mathrm{N})$.
Measurement of modulus of rigidity

The modulus of rigidity, $G$, of glulam was measured by the vibration test method. $G$ was calculated from the following:

$G=\left[\frac{f_{T-n} \times 2 \times l}{n}\right]^{2} \times \frac{\rho \times I}{K_{\mathrm{t}}}$

where $f_{T-n}$ is the resonance frequency (Hz), $n$ represents the resonance mode, $l$ is the length of the specimen $(\mathrm{m}), \rho$ is the density of the specimen $\left(\mathrm{kg} / \mathrm{m}^{3}\right)$, and $I$ is the moment of the inertia of the specimen $\left(\mathrm{m}^{4}\right) . K_{\mathrm{t}}$ is the torsional constant $\left(\mathrm{m}^{4}\right)$, which is expressed as follows:

$$
K_{\mathrm{t}}=b h^{3} \xi
$$

where $b$ is the width of the specimen (m), $h$ is the thickness of the specimen $(\mathrm{m})$, and $\xi$ is calculated as follows:

$$
\xi=\frac{1}{3}\left[1-\frac{192}{\pi^{5}} \frac{h}{b} \sum_{n=0}^{\infty} \frac{1}{(2 n+1)^{5}} \tanh \frac{(2 n+1) \pi b}{2 h}\right]
$$

\section{Measurement of stress and strain}

In order to study changes in the $M O E$ of the laminae, a strain gauge (FLA-5-11, Tokyo Sokki Kenkyujo) was affixed to the lateral sides of the laminae (Fig. 1). The length of the gauge was $5 \mathrm{~mm}$, the resistance was about $120 \pm 0.3 \Omega$, and the gauge factor was $2.12 \% \pm 1 \%$.

The measurement principle was based on the balance of a Wheatstone bridge circuit. Owing to changes in the wire length of the strain gauge, the resistance also changed. The signal was input to an eight-channel amplifier and stored in a digital data logger.

Before the strain gauge was affixed to the lumber, the surface was sanded in order to apply epoxy glue. A pair of 1-m-long wires was soldered to the wire terminal after the strain gauge was affixed. The strain and loading were recorded from the compression side, the center axis, to the tension position, respectively. The data from the loading cell and strain gauge were stored in a data logger, the strain-stress relation was plotted, and $M O E$ values of the laminae were calculated. The stresses of the laminae were calculated from Eq. 5, and the values of $e_{1}, e_{2}$, and $e_{3}$ were calculated from Eq. 6:

$\sigma=\frac{M E y}{\sum\left(E_{i} I_{i}\right)}$

$e=\frac{\sigma}{\varepsilon}$

where $M$ is the bending moment, $E$ is the modulus of elasticity of the laminae, $y$ is the offset distance of the laminae from the neutral axis, $I$ is the moment of inertia, and $\varepsilon$ is the strain of the laminae.

In this study, "free condition" indicated that the laminae were not bonded together, while "constrained condition" 
indicated that laminae were bonded. Hence, comparison of $e_{1}, e_{2}$, and $e_{3}$ (constrained condition) with $E_{1}, E_{2}$, and $E_{3}$ (free condition) can describe the bonding effect of the glulam.

Relationship between the predicted and observed $M O E$

The predicted $M O E\left(E_{\mathrm{b}}\right)$ was calculated by substituting the $M O E$ of the laminae calculated from the strain gauge, the $M O E$ of the RF adhesive $\left(e_{\mathrm{r}}\right)$ of $17.0 \mathrm{GPa}$, and thickness $\left(t_{\mathrm{r}}\right)$ of $0.218 \mathrm{~mm}$, into Eq. $2 .^{16}$ The observed $M O E$ was calculated from Eq. 3.

Position change of the neutral axis during bending test

To study the displacement of the neutral axis, the position of the strain gauge was assigned to the $y$-axis, and the value of the strain gauge was assigned to the $x$-axis. Because the longitudinal stress is zero at the neutral axis, the stress on the compressive side is negative while it is positive on the tensile side. The relationship of strain with its position can be expressed as a linear regressive formula of the form $y=a+b x$. When $x$ is set to zero, the value of $y$ is the position of the neutral axis.

\section{Results and discussion}

Bending properties of laminae

The $M O E$ of the Japanese cedar laminae ranged from 8.0 to $16.4 \mathrm{GPa}$ and the average was $10.5 \mathrm{GPa}$. Most were within $7.0-13.0 \mathrm{GPa}$ which were $87.9 \%$ of total Japanese cedar specimens as shown in Fig. 3. On the other, the MOE of the laminae of southern pine ranged from 9.2 to $20.9 \mathrm{GPa}$ and the average was $14.9 \mathrm{GPa}$. Most were within $11.0-19.0 \mathrm{GPa}$ which were $86.2 \%$ of total southern pine specimens as shown in Fig. 4.

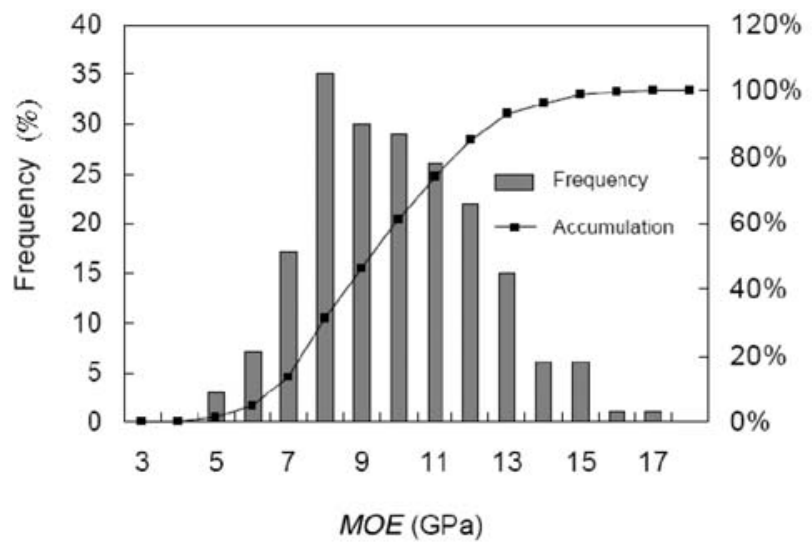

Fig. 3. Frequency of $M O E$ of laminae made of Japanese cedar
Generally, studies on the relationship between wood density and modulus of elasticity are based on small clear wood. Markwart and Wilson ${ }^{19}$ induced the relationship and indicated that the density is the important factor affecting wood strength. In the study, although $M O E$ increased with an increase in density and the statistical result was significant, the determination coefficient, $R^{2}=$ $0.28-0.31$, was not high (Fig. 5). The value was very close to $R^{2}=0.314$ to 0.624 that Wang and Lin $^{6}$ and Wang and $\mathrm{Ko}^{7}$ reported in their studies of the relationship between $M O E$ and $M O R$ for Japanese cedar. Similarly, Doyle and Markwart ${ }^{20}$ also found that both the MOR and MOE increased with an increase in the wood density in an investigation of lumber of six different grades and four different dimensions; however, the $R^{2}$ values were only 0.244 and 0.377 , respectively. Therefore, the effect of wood density on the strength of lumber was not as significant as it was on small clear wood pieces.

Burdzik and Nkwera ${ }^{4}$ also conducted similar research on Eucalyptus grandis. Their results indicated that wood density cannot accurately predict the $M O E$ and $M O R$ because wood density is not the only or even an excellent factor for predicting the mechanical properties of wood.

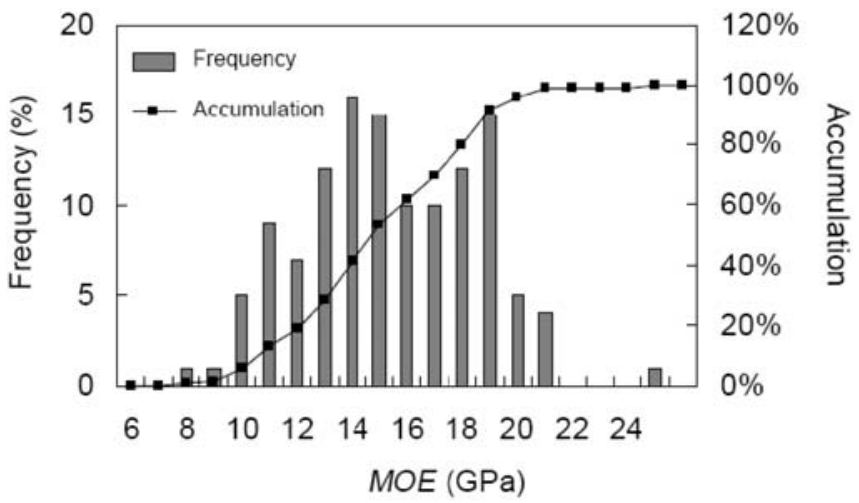

Fig. 4. Frequency of $M O E$ of laminae made of southern pine

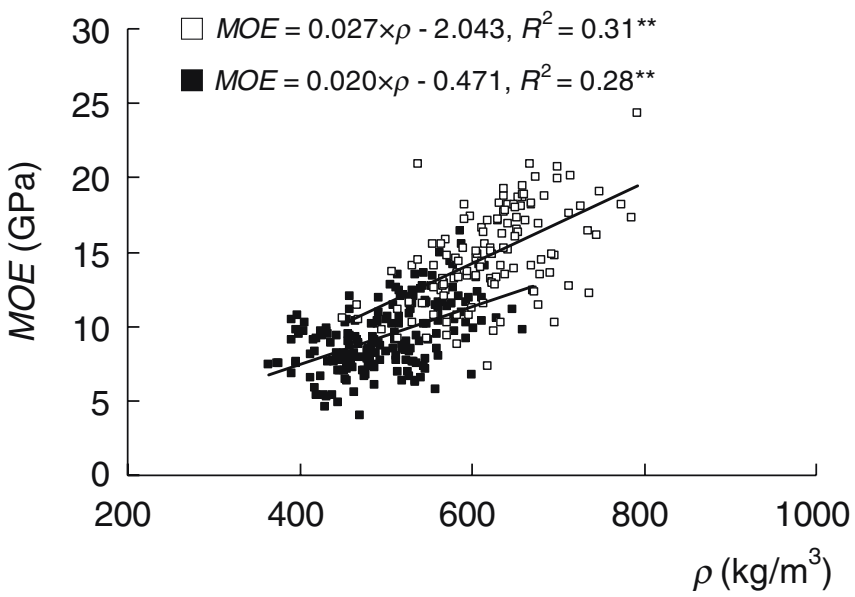

Fig. 5. Relationship between $M O E$ and density of Japanese cedar (filled squares) and southern pine (open squares) laminae 
Table 1. The values of modulus of elasticity $(M O E)$ of glulam

\begin{tabular}{|c|c|c|c|c|c|c|c|c|c|}
\hline Glulam & $\begin{array}{l}E_{\mathrm{bf}} \\
(\mathrm{Gpa})\end{array}$ & $\begin{array}{l}E_{\mathrm{b}} \\
(\mathrm{Gpa})\end{array}$ & $\begin{array}{l}E_{\text {bsg }} \\
(\mathrm{Gpa})\end{array}$ & $\begin{array}{l}E_{\text {bsa }} \\
(\mathrm{Gpa})\end{array}$ & $\begin{array}{l}G \\
\text { (Gpa) }\end{array}$ & $E / G$ & $\begin{array}{l}E_{\mathrm{p}} \\
\text { (Gpa) }\end{array}$ & $\begin{array}{l}\sigma \\
(\mathrm{Mpa})\end{array}$ & $\begin{array}{l}M O R \\
\text { (Mpa) }\end{array}$ \\
\hline \multicolumn{10}{|c|}{ Japanese cedar } \\
\hline GJI & $12.9^{\mathrm{a}}$ & $12.7^{\mathrm{a}}$ & 12.3 & 12.2 & 0.88 & 14.47 & $13.4^{\mathrm{a}}$ & 54.2 & $61.9^{\mathrm{a}}$ \\
\hline GJ3H & $12.7^{\mathrm{a}}$ & $12.2^{\mathrm{a}}$ & 12.4 & 12.3 & 0.88 & 13.89 & $12.9^{\mathrm{a}}$ & 49.3 & $61.1^{\mathrm{a}}$ \\
\hline $\mathrm{GJ} 2 \mathrm{H}$ & $11.0^{\mathrm{b}}$ & $10.6^{\mathrm{b}}$ & 10.2 & 10.1 & 0.79 & 13.38 & $11.2^{\mathrm{b}}$ & 42.9 & $53.2^{\mathrm{b}}$ \\
\hline GJ1H & $9.9^{\mathrm{b}}$ & $10.0^{\mathrm{b}}$ & 9.9 & 9.9 & 0.76 & 13.23 & $10.6^{\mathrm{b}}$ & 38.4 & $48.3^{\mathrm{b}}$ \\
\hline \multicolumn{10}{|c|}{ Southern pine } \\
\hline GSI & $18.6^{\mathrm{a}}$ & $19.6^{\mathrm{a}}$ & 20.9 & 21.0 & 1.05 & 18.72 & $20.6^{\mathrm{a}}$ & 68.0 & $78.4^{\mathrm{a}}$ \\
\hline GS3H & $18.2^{\mathrm{a}}$ & $18.8^{\mathrm{a}}$ & 19.6 & 19.6 & 0.98 & 19.09 & $19.8^{\mathrm{a}}$ & 60.4 & $73.6^{\mathrm{a}}$ \\
\hline GS2H & $14.9^{\mathrm{b}}$ & $16.1^{\mathrm{b}}$ & 13.7 & 13.6 & 0.88 & 18.16 & $16.9^{\mathrm{b}}$ & 59.4 & $73.1^{\mathrm{a}}$ \\
\hline GS1H & $12.5^{\mathrm{c}}$ & $13.9^{c}$ & 13.5 & 13.5 & 0.87 & 16.03 & $14.6^{\mathrm{c}}$ & 61.1 & $74.7^{\mathrm{a}}$ \\
\hline
\end{tabular}

$\overline{E_{\mathrm{bf}}}$, predicted $M O E$ of glulam under a free condition; $E_{\mathrm{b}}$, observed $M O E$ of glulam; $E_{\mathrm{bsg}}, M O E$ of glulam calculated from the strain gauge method; $E_{\mathrm{bsa}}, M O E$ of glulam after the neutral axis was modified; $E_{\mathrm{p}}$, pure $M O E ; M O R$, modulus of rupture

Data followed by different lowercase letters are significantly different for each species $(P<0.05)$ by ANOVA

Table 2. The correlations among $E_{\mathrm{b}}, E_{\mathrm{p}}, E_{\mathrm{bf}}, E_{\mathrm{bsg}}, E_{\mathrm{bsa}}, E_{3}, e_{3}, M O R$, and $\sigma$ values analyzed by the linear regression formula $(y=a x+b)$ for Japanese cedar and southern pine glulam

\begin{tabular}{llllllr}
\hline $\begin{array}{l}\text { Wood species of } \\
\text { glulam }\end{array}$ & $y$ & $x$ & $a$ & $b$ & $R^{2}$ & $F$ value \\
\hline Japanese cedar & $E_{\mathrm{b}}$ & $E_{\mathrm{bf}}$ & 0.852 & 1.457 & 0.82 & $85^{* *}$ \\
& $E_{\mathrm{p}}$ & $E_{\mathrm{bf}}$ & 0.901 & 1.541 & 0.82 & $85^{* *}$ \\
Southern pine & $E_{\mathrm{b}}$ & $E_{\mathrm{bf}}$ & 0.909 & 2.581 & 0.96 & $443^{* *}$ \\
& $E_{\mathrm{p}}$ & $E_{\mathrm{bf}}$ & 0.955 & 2.658 & 0.96 & $443^{* *}$ \\
Both Japanese & $E_{\mathrm{p}}$ & $E_{\mathrm{bf}}$ & 1.175 & -1.130 & 0.95 & $750^{* *}$ \\
cedar and & $E_{\mathrm{p}}$ & $E_{\mathrm{bsg}}$ & 0.875 & 2.301 & 0.97 & $1052^{* *}$ \\
southern pine & $E_{\mathrm{p}}$ & $E_{\mathrm{bsa}}$ & 0.865 & 2.481 & 0.97 & $971^{* *}$ \\
& $E_{\mathrm{p}}$ & $E_{3}$ & 1.028 & 0.325 & 0.92 & $422^{* *}$ \\
& $E_{\mathrm{p}}$ & $e_{3}$ & 0.769 & 3.598 & 0.96 & $775^{* *}$ \\
& $E_{\mathrm{p}}$ & $\sigma$ & 0.271 & 0.306 & 0.67 & $73^{* *}$ \\
& $M O R$ & $E_{\mathrm{p}}$ & 2.661 & 25.55 & 0.64 & $67^{* *}$ \\
& $M O R$ & $\sigma$ & 1.076 & 7.291 & 0.96 & $842^{* *}$ \\
\hline
\end{tabular}

$M O E$ of glulam

$E_{\mathrm{bf}}$ represents the $M O E$ of the glulam under a free condition, obtained by substituting the values of $E_{1}-E_{3}$ into Eq. 2 . $E_{\text {bsg }}$ represents the $M O E$ of the glulam determined by substituting $e_{1}-e_{3}$ from the strain gauge method into the same formula. Both results are shown in Table 1.

In the bending test, the results showed (Table 1 ) that the $M O E$ of the four groups occurred in the order of GJI > GJ3H $>$ GJ2H > GJ1H for Japanese cedar. Similar results were obtained for the southern pine lumbers.

Analysis of variance (ANOVA) showed no significant difference between the heterogeneously graded combination GJI group and the homogeneously graded combination $\mathrm{GJ} 3 \mathrm{H}$ for Japanese cedar. The same was found for the heterogeneously graded combination GSI group and the homogeneously graded combination GS3H for southern pine. In other words, the heterogeneously graded combination glulam improved the performance of the laminae over those of the homogeneously graded combination ones.

For prediction of the $M O E$ of glulam made from Japanese cedar, results showed that the predicted $\operatorname{MOE}\left(E_{\mathrm{bf}}\right)$ of glulam was about $0.2 \%-5.7 \%$ larger than the observed $M O E$ $\left(E_{\mathrm{b}}\right)$, and there was a linear relationship between them with $R^{2}=0.82$ (Table 2). However, the observed $\operatorname{MOE}\left(E_{\mathrm{b}}\right)$ of glulam made from southern pine was about $0.5 \%-11.4 \%$ larger than the predicted $\operatorname{MOE}\left(E_{\mathrm{bf}}\right)$, and there was also a linear relationship between them with $R^{2}=0.96$ (Table 2).

The modulus of rigidity, $G$, of glulum ranged from 0.76 to $0.88 \mathrm{GPa}$ for Japanese cedar glulam, and from 0.87 to $1.05 \mathrm{GPa}$ for southern pine glulam. The value of $G$ increased with increased glulam grading. The $E / G$ ratio was calculated from $E_{\mathrm{b}}$ and $G$ of the first resonance mode; therefore, the $E /$ $G$ ratios of Japanese cedar and southern pine were within the ranges of 13.23-14.47 and 16.03-19.09, respectively. Bodig and Jayne ${ }^{21}$ indicated that the $E / G$ ratio of wood ranged from 14 to 20, while Ohlsson and Perstorper ${ }^{22}$ found that the $E / G$ ratio of clear Norway spruce is 10.7 . Isoda et al. ${ }^{23}$ found that the $E / G$ ratio ranged from 14.1 to 56 and the average was 28.3 in research of glulam bending and fracture.

Owing to the bending beam being subjected to the moment and vertical shear force, the actual deflection included a component due to shear. In other words, the shear deflection should be considered in research, although its effect is trivial. Bodig and Jayne ${ }^{21}$ also indicated that the pure $M O E$ obtained by ignoring shear deflection can be described by the following expression:

$$
\frac{M O E}{E_{\mathrm{p}}}=\frac{(L / h)^{2}}{(L / h)^{2}+C}
$$


Table 3. The differences of lamina $M O E$ s between the free condition and constrained condition

\begin{tabular}{|c|c|c|c|c|c|}
\hline \multirow[t]{2}{*}{ Type of glulam } & \multirow[t]{2}{*}{$\begin{array}{l}\text { Position of the } \\
\text { lamina }\end{array}$} & \multicolumn{2}{|c|}{$\begin{array}{l}\text { Homogeneously graded } \\
\text { combination }\end{array}$} & \multicolumn{2}{|c|}{$\begin{array}{l}\text { Heterogeneously graded } \\
\text { combination }\end{array}$} \\
\hline & & $E / E_{\mathrm{bf}}$ & $e / E_{\mathrm{p}}$ & $E / E_{\mathrm{bf}}$ & $e / E_{\mathrm{p}}$ \\
\hline \multirow[t]{3}{*}{ Japanese cedar } & $E_{1}$ & $0.91(0.8)$ & $0.73(12.7)$ & $0.63(2.0)$ & $0.57(10.6)$ \\
\hline & $E_{2}$ & $0.94(0.6)$ & $0.89(11.3)$ & $0.66(2.0)$ & $0.61(9.9)$ \\
\hline & $E_{3}$ & $1.00(0.3)$ & $0.97(5.8)$ & $1.12(0.6)$ & $0.99(5.4)$ \\
\hline \multirow[t]{3}{*}{ Southern pine } & $E_{1}$ & $0.93(0.7)$ & $0.91(6.8)$ & $0.65(8.5)$ & $0.68(9.5)$ \\
\hline & $E_{2}$ & $0.98(0.3)$ & $0.92(9.2)$ & $0.86(0.5)$ & $0.88(11.8)$ \\
\hline & $E_{3}$ & $1.02(0.1)$ & $1.00(2.1)$ & $1.07(0.3)$ & $1.09(4.8)$ \\
\hline
\end{tabular}

Values in parentheses are coefficients of variation (\%)

$E_{\mathrm{b},}$, predicted $M O E$ of glulam under free condition; $E_{\mathrm{p}}$, pure $M O E$ of glulam; $E, M O E$ of lamina under a free condition; $e, M O E$ of lamina under a constrained condition

where $M O E$ is observed, and $E_{\mathrm{p}}$ is the pure $M O E, L / h$ is the ratio of span to thickness, and $C$ is equal to 15.05 when the beam is subjected to four-point bending.

Theoretically, the pure $M O E$ is larger than the observed $E_{\mathrm{b}}$; hence, the average $E_{\mathrm{b}} / E_{\mathrm{p}}$ ratios of Japanese cedar and southern pine are 0.946 and 0.952 , respectively. Isoda et al. ${ }^{23}$ also indicated the $E_{\mathrm{b}} / E_{\mathrm{p}}$ ratio is 0.98 . The $E_{\mathrm{p}}$ of Japanese cedar is about $1.3 \%-7.2 \%$ greater than $E_{\mathrm{bf}}$, while $E_{\mathrm{p}}$ of southern pine is about $8.4 \%-17.1 \%$ greater than $E_{\mathrm{b} \text {. }}$.

Apparently, the MOR of laminae of Japanese cedar was less than that of southern pine. Hence, the overall MOR of the glulam made from Japanese cedar remained inferior to that of the glulam prepared from Southern pine. Considering only the grade of the laminae and the properties of the glulam, the $M O E$ of the homogeneously graded combination glulam was very close to those of their laminae of Japanese cedar and southern pine. The MOE values of the heterogeneously graded combination glulam were $23 \%$ and $31 \%$ larger than the average $M O E$ of their laminae for Japanese cedar and southern pine, respectively.

The MOR results for both Japanese cedar and southern pine are given in Table 1. After ANOVA analysis, the statistical results showed that there was no significant difference between the heterogeneously graded combination group of GJI and the homogeneously graded combination group of GJ3H for Japanese cedar. No difference was found among any of the graded groups for southern pine. The overall MOR values of southern pine glulams were higher than those of Japanese cedar.

Furthermore, the regression analysis showed that there was a positive linear relationship between $M O R$ and $M O E$ with $R^{2}=0.64$. A positive linear relationship was also found between $M O R$ and the ultimate bending stress $(\sigma)$ with $R^{2}=$ 0.96 . The ultimate bending stress $(\sigma)$ also had a linear relationship with $E_{\mathrm{p}}$ of glulam with $R^{2}=0.67$. Hence, $\sigma$ could still predict the $E_{\mathrm{p}}$ of glulam.

Stress analysis of the glulam

In the bending test, the load-strain diagrams of the glulams are shown as Figs. 6 and 7. In comparison of the strain of the

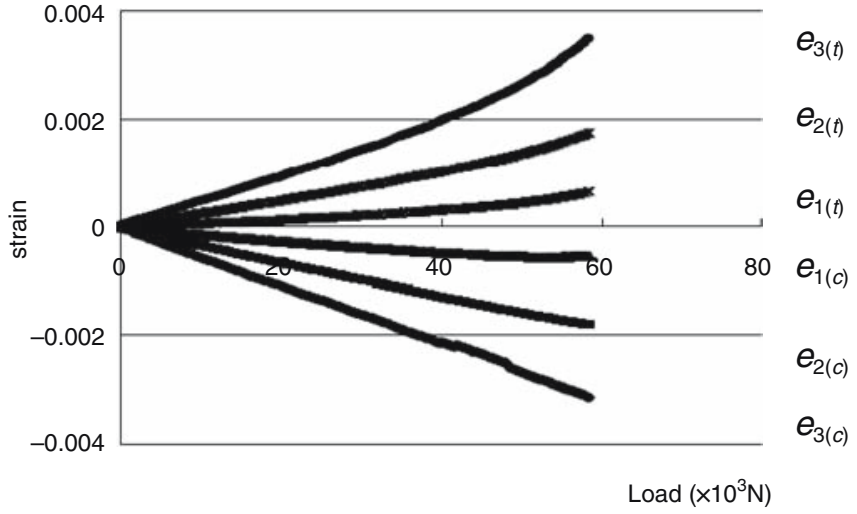

Fig. 6. Load-strain diagram of GJI glulam. $e_{1(\mathrm{c})}-e_{3(\mathrm{c})}$ shows the $M O E$ of laminae on the compression side; $e_{1(\mathrm{t})}-e_{3(\mathrm{t})}$ shows the $M O E$ of laminae on the tension side

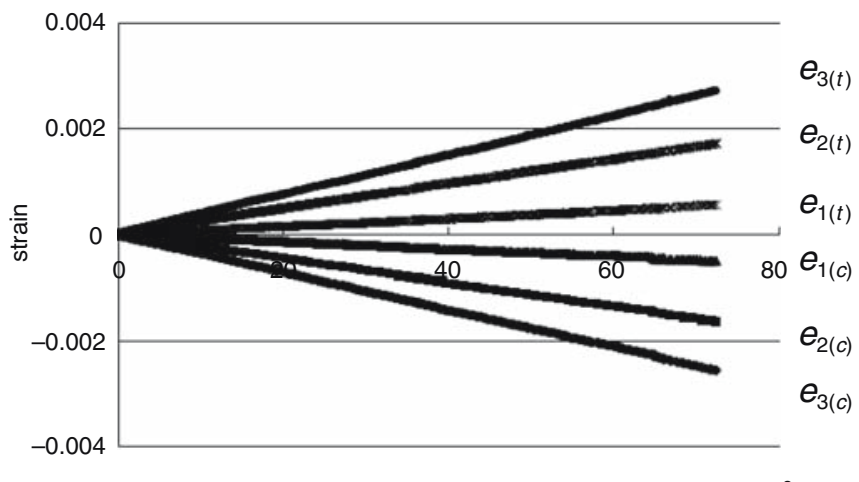

$\operatorname{Load}\left(\times 10^{3} \mathrm{~N}\right)$

Fig. 7. Load-strain diagram of GSI glulam

outermost laminae of all the glulams at the same loading, less strain was found to occur for higher grades of the external lamina. That is, the strain of the external lamina increased as its grade decreased.

On the other hand, the stress of the laminae of the glulam can be calculated from Eq. 5. According to Hook's 


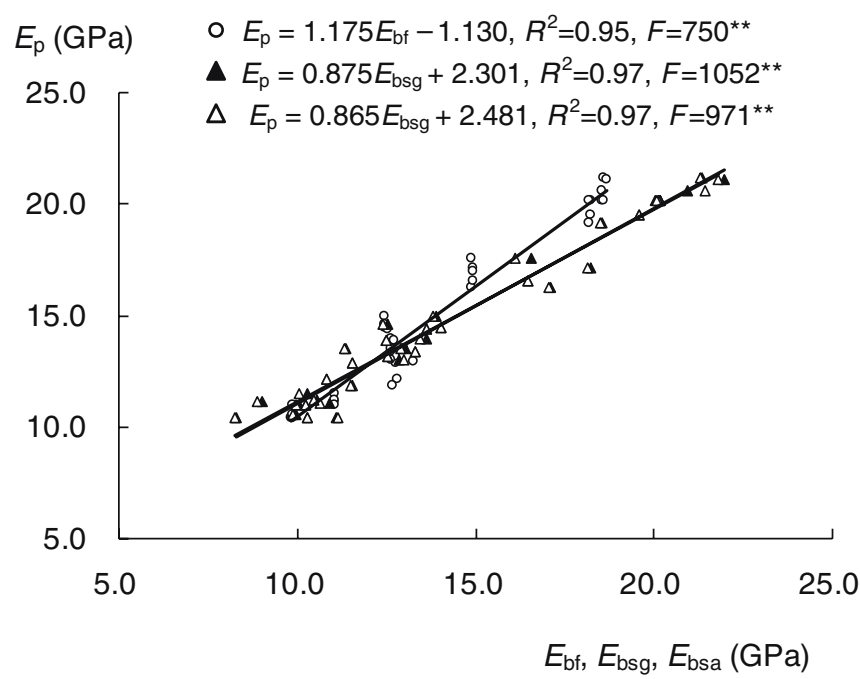

Fig. 8. Relationships of $E_{\mathrm{p}}$ with $E_{\mathrm{bf}}, E_{\mathrm{bsg}}$, and $E_{\mathrm{bsa}}$. Circles, $E_{\mathrm{bf}}$; filled triangles, $E_{\mathrm{bsg}}$; open triangles, $E_{\mathrm{bsa}}$

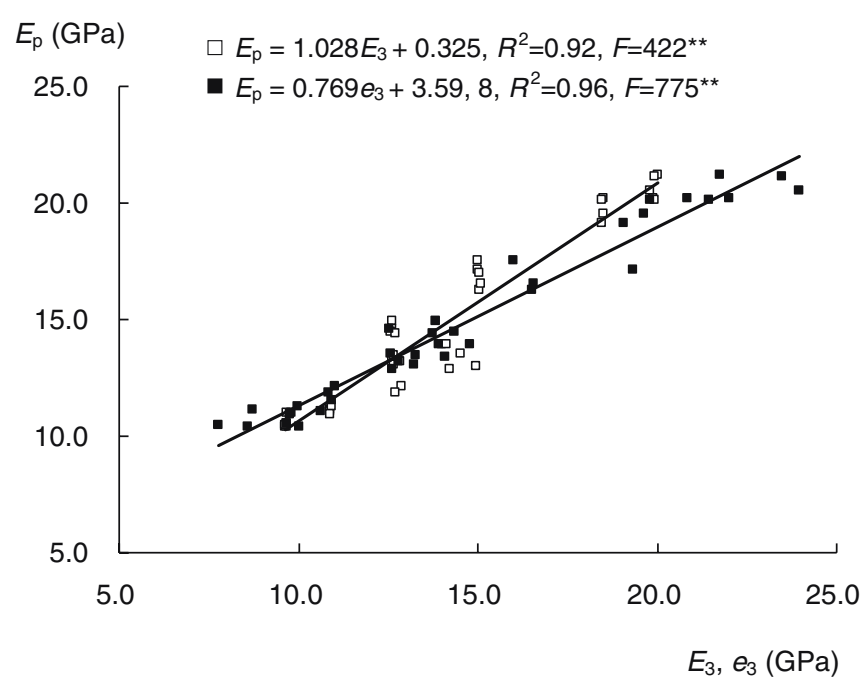

Fig. 9. Relationship of $E_{\mathrm{b}}$ of the glulam with $E_{3}$ and $e_{3}$ of the outermost lamina. Open squares, $E_{3}$; filled squares, $e_{3}$

law, the modulus of elasticity $(e)$ of the laminae can easily be calculated from the stress divided by the strain. When an individual $M O E$ of a lamina is acquired and substituted into Eq. 2, the $E_{\text {bsg. }}$ (MOE of the glulam measured by the strain gauge method) was calculated as shown in Table 1 . The average $E_{\mathrm{b}}$ was about $0.6 \%-3.6 \%$ larger than the $E_{\mathrm{bsg}}$ for Japanese cedar; however, the average $E_{\mathrm{b}}$ was about $0.5 \%$ $6.9 \%$ less than the $E_{\text {bsg }}$ for southern pine. In other words, the values of $E_{\mathrm{b}}$ and $E_{\mathrm{bsg}}$ were very similar.

Comparing pure $M O E\left(E_{\mathrm{p}}\right)$ with $M O E$ calculated from the strain gauge method, the $E_{\mathrm{p}}$ of Japanese cedar glulam was about $4.0 \%-9.6 \%$ greater than its $E_{\text {bsg. }}$. The observed $M O E$ before modification of southern pine was less than $E_{\text {bsg }}$; however, the $E_{\mathrm{p}}$ was $0.9 \%-23.5 \%$ greater than $E_{\text {bsg }}$ except for the GSI group. The $E_{\mathrm{p}}$ of the GSI group was still about $1.2 \%$ less than $E_{\text {bsg. }}$.

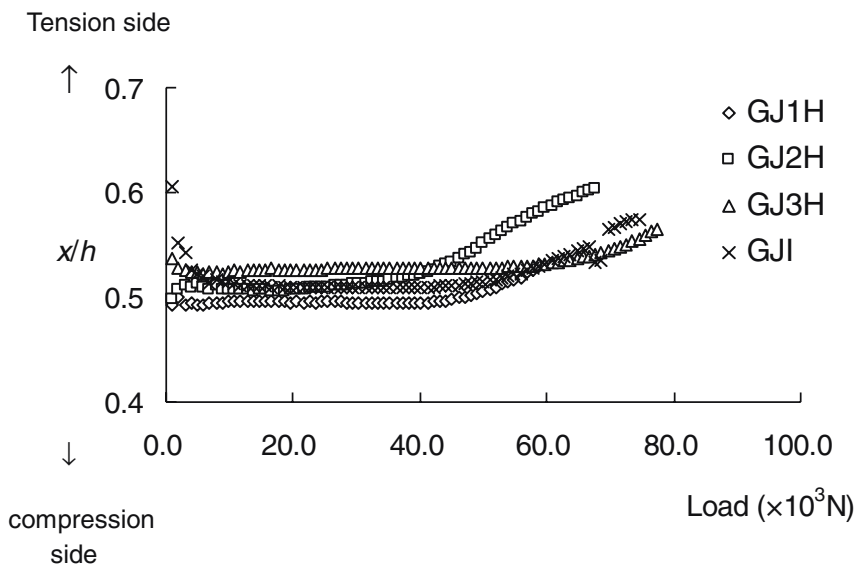

Fig. 10. Shift in the neutral axis in the glulam of Japanese cedar

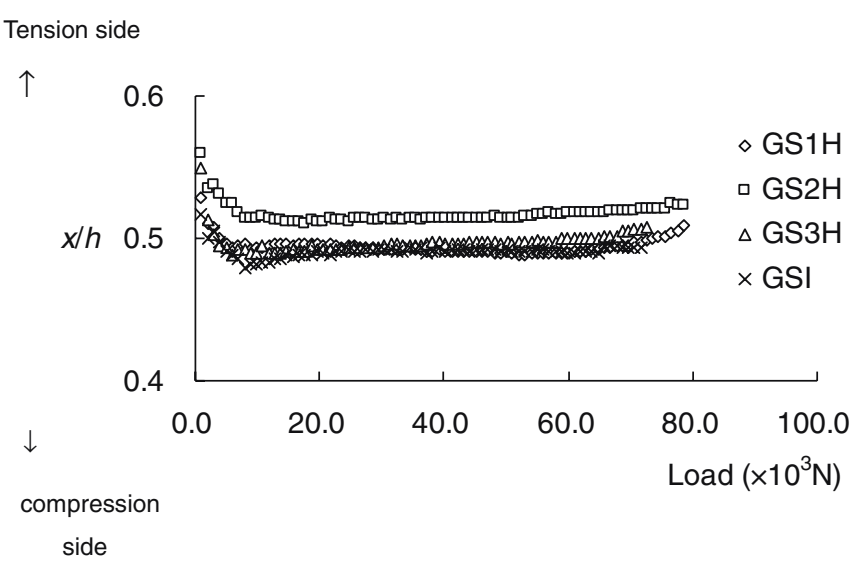

Fig. 11. Shift in the neutral axis in the glulam of southern pine

In the analysis of the linear relationships of $E_{\mathrm{p}}$ with $E_{\mathrm{bf}}$, $E_{\text {bsg }}$, and $E_{\text {bsa }}$, the regression lines are shown in Fig. 8. $E_{\mathrm{p}}$ increased with increases in $E_{\mathrm{bf}}, E_{\mathrm{bsg}}$, and $E_{\text {bsa }}$, and their $R^{2}$ values were $0.95,0.97$, and 0.96 , respectively.

Considering the $M O E$ of laminae in the free condition and the constrained condition, the $e$ value measured by the strain gauge method was very close to the $E$ value under a free condition. Previous results showed that the $E$ value was greater than the $e$ value for Japanese cedar; however, the $e$ value was greater than the $E$ values for southern pine. Differences in the $M O E$ values between the free condition and the constrained condition of the laminae at the same level of observed $M O E$ for the heterogeneously graded and homogeneously graded combination glulams are listed in Table 3.

Because the outermost laminae of glulam had the greatest effect on the overall properties, the relationships of the $E$ and $e$ values with $E_{\mathrm{p}}$ of the glulam were analyzed by linear regression and the $R^{2}$ were 0.92 and 0.96 , respectively (Fig. $9)$. Hence, the properties of the glulam can accurately be predicted by the outermost laminae. Moreover, the $e$ value 
can predict the overall $M O E$ more precisely due to its origin from the stress analysis.

Shift in the neutral axis of the glulam

The position of the neutral axis was determined by the strain gauge method. The position of the neutral axis is expressed as $x / h$, where $x$ is the distance between the axis and the top lamina edge of the glulam, and $h$ is the thickness of the glulam. The value of $x / h$ ranges from 0 to 1 and equals to 0.5 if the beam is homogeneous. However, in such cases, $x / h$ is a little larger than 0.5 because wood is not a homogeneous material. That is, the actual neutral axis is below the central axis. Furthermore, the accuracy of the strain gauge also affects $x / h$. A shift in the neutral axis is slight within the proportional limit range. However, the tensile strength of wood is significant larger than the compressive strength, and the tensile deflection is smaller than the compressive deflection. The neutral axis shifts downward when the loading increases during the bending test and becomes significant in the plastic region (Figs. 10, 11). Kollmann and $\operatorname{Cote}^{24}$ also indicated that the position of the neutral axis varies with the laminae properties of the glulam. Owing to the differences between the compression part and tensile part of the gluam, the tensile stress is larger than the compressive stress; hence, the neutral axis shifts downward.

The relationship of strain with its position can be expressed as a linear regression in the form of $y=a+b x$. When $x$ is set to zero, the $y$ value is the position of the neutral axis. After the actual neutral axis is acquired, the modified $M O E$ $\left(E_{\text {bsa }}\right)$ of the glulam can be calculated. We compared $E_{\text {bsg }}$ measured with the strain gauge with $E_{\text {bsa }}$ and found no significant difference. Similarly, there was no significant difference between $E_{\mathrm{bsa}}$ and $E_{\mathrm{p}}$. The average $E_{\mathrm{p}}$ was $4.1 \%-$ $11.3 \%$ larger than $E_{\mathrm{bsa}}$ for Japanese cedar; however, the average $E_{\mathrm{p}}$ was $0.9 \%-24.5 \%$ larger than $E_{\mathrm{bsa}}$ for southern pine except for the GSI group, for which the $E_{\mathrm{p}}$ values were $1.5 \%$ less than $\mathrm{E}_{\mathrm{bsa}}$.

\section{Conclusions}

The modulus of elasticity of the laminated element increases as its density increases; however, the wood density is not the only evaluated factor. The $M O E$ of glulam $\left(E_{\mathrm{bsg}}\right)$ measured by the strain gauge method was very close to the observed $M O E$ of glulam $\left(E_{\mathrm{b}}\right)$ with a significant linear relationship. The MOE (e) of the laminae measured by the strain gauge method was very close to that $(E)$ under the "free condition" before bonding. The difference between the modified $M O E$ $\left(E_{\mathrm{bsa}}\right)$ and $E_{\mathrm{bsg}}$ was not significant. The $M O E$ of glulams made of heterogeneously graded lumbers were about $23 \%$ and $31 \%$ larger than the average $M O E$ of their laminae for Japanese cedar and southern pine, respectively.

The actual neutral axis was just below the longitudinal central line. It shifted slightly within the proportional limit range and moved significantly downward when the load exceeded the limit.
Acknowledgments The authors thank the National Science Council of ROC for financial support under NSC91-2313-B-002-396, and Prof. Min-Chyuan Yeh, Department of Wood Industry, National Pingtung University of Science and Technology, for valuable suggestions and help.

\section{References}

1. Peterson J, Madson G, Moody RC (1981) Tensile strength of one-, two-, and three-ply glulam members of 2 by 6 Douglas-fir. Forest Prod J 31:42-48

2. Ross RJ, Pellerin RF (1994) Nondestructive testing for assessing wood members in structure: a review. FPL-GTR-70. USDA Forest Service, Forest Products Laboratory, Madison, WI

3. Erikson RG, Gorman TM, Green DW, Graham D (2000) Mechanical grading of lumber sawn from small-diameter lodgepole pine, ponderosa pine, and grand fir trees from northern Idaho. Forest Prod J 50:59-65

4. Burdzik WMG, Nkwera PD (2002) Transverse vibration tests for prediction of stiffness and strength properties of full size Eucalyptus grandis. Forest Prod J 52:63-67

5. Wang X, Ross RJ, Mattson JA, Erickson JR, Forsman JW, Geskse EA, Wehr MA (2002) Nondestructive evaluation techniques for assessing modulus of elasticity and stiffness of small-diameter logs. Forest Prod J 52:79-85

6. Wang SY, Lin SH (1996) Effect of plantation spacing with quality of visually graded lumber and mechanical properties of Taiwangrown Japanese cedar. Mokuzai Gakkaishi 42:435-444

7. Wang SY, Ko CY (1998) Dynamic modulus of elasticity and bending properties of large beams of Taiwan-grown Japanese cedar from different plantation spacing sites. Mokuzai Gakkaishi 44:6268

8. Hernandez R, Moody RC (1992) Improved performance of southern pine structural glued-laminated timber. Research Paper FPLRP-514. USDA Forest Service, Forest Products Laboratory, Madison, WI

9. Manbeck HB, Janowiak JJ, Blankenhorn PR, Labosky P, Moody RC, Hernandez R (1993) Red maple glulam timber beam performance. Research Paper FPL-RP-519. USDA Forest Service, Forest Products Laboratory, Madison, WI

10. Janowiak JJ, Manbeck HB, Hernandez R, Moody RC, Blankenhorn PR, Labosky P (1995) Efficient utilization of red maple lumber in glued-laminated timber beams. Research Paper FPL-RP-541. USDA Forest Service, Forest Products Laboratory, Madison, WI

11. Moody RC, Hernandez R, Davalos JF, Sonti SS (1993) Yellow poplar glulam timber beam performance. Research Paper FPLRP-520. USDA Forest Service, Forest Products Laboratory, Madison, WI

12. Falk RH (1997) Design and performance aspects of United States and European glulam. Proceedings of the Conference on Research Standardization Applications, Institute for Steel Construction, Wood Construction, and Industrial Construction, Technical University Graz, Austria, 6 June 1997, pp C/2-1-C/2-21

13. Falk RH, Colling F (1995) Laminating effect in glued-laminated timber beams. J Struct Eng ASCE 121:1857-1863

14. Lee JJ, Park JS, Kim KM, Oh JK (2005) Prediction of bending properties for structural glulam using optimized distributions of knot characteristics and laminar MOE. J Wood Sci 51:640-647

15. Yamada M, Takada M, Sano A (2001) Fire-resistance performance of structural LVL (4). Abstracts of the 51st Annual Meeting of the Japan Wood Research Society, p 425

16. Wang SY, Cho JL (1985) Studies on the dynamic and acoustic behaviors of wood (III). Forest Prod Ind 4:2-26

17. Okuma M (1967) Studies on the mechanical properties of plywood. Bull Tokyo Univ Forest 63:1-60

18. Wang SY, Chang T (1978) Studies on the flexural properties of laminated beams with different wood species (1). Bending modulus of elasticity. Q J Chinese Forest 11:43-52

19. Markwart LJ, Wilson TRC (1935) Strength and related properties of woods grown in the United States. USDA Technical Bulletin 479, Washington DC 
20. Doyle DV, Markwart LJ (1966) Properties of southern pine in relation to strength grading of dimension lumber. Research Paper FPL-64. USDA Forest Service, Forest Products Laboratory, Madison, WI

21. Bodig J, Jayne BA (1982) Mechanics of wood and wood composites. Van Nostrand Reinhold, New York

22. Ohlsson S, Perstorper M (1992) Elastic wood properties from dynamic tests and computer modeling. J Struct Eng ASCE 18:26772690
23. Isoda $\mathrm{H}$, Mori $\mathrm{T}$, Sasagawa A (2000) The resistance and fracture mechanisms of glulam beams in bending. J Struct Construct Eng 529:13-20

24. Kollmann F, Cote WA (1968) Principles of wood science and technology, vol 1. Solid wood. Springer, Berlin Heidelberg New York, pp 359-379 